\title{
"Premature luteinization" in the era of GnRH analogue protocols: time to reconsider
}

\author{
Johnny S. Younis
}

Received: 8 April 2011 / Accepted: 13 May 2011 /Published online: 26 May 2011

(C) Springer Science+Business Media, LLC 2011

\section{Background}

The introduction of the GnRH analogues and their employment into the routine practice of controlled ovarian hyperstimulation $(\mathrm{COH})$ for assisted reproductive technologies (ART) was expected to abolish premature LH and consequently follicular progesterone $(\mathrm{P})$ elevations. More than two decades have passed since the GnRH agonist was brought into practice and more than one decade since the $\mathrm{GnRH}$ antagonist was commenced, however moderate $\mathrm{P}$ elevation, before the day of hCG administration, is continuing to complicate a significant part of ART cycles employing both protocols, ranging from 12.4 to $52.3 \%$ [1].

Despite its wide occurrence there has been an ongoing hot and active debate in the literature concerning the effect of this phenomenon on ART treatment outcome. While some investigators advocate no affect on the probability of clinical pregnancy achievement [1] others support an adverse effect on ART outcome through a detrimental effect on endometrial receptivity $[2,3]$.

Capsule FSH rather LH is the cause of follicular $\mathrm{P}$ elevation in a GnRH analogue cycles and LH supplementation lowers P level. Accordingly, the term "premature luteinization" should be ameliorated and a new terminology and definition are suggested.

J. S. Younis $(\bowtie)$

Reproductive Medicine Unit, Department of Obstetrics

\& Gynecology, Poriya Medical Center,

Tiberias 15208 , Israel

e-mail: jsy@netvision.net.il

J. S. Younis

e-mail: jyounis@poria.health.gov.il

J. S. Younis

Rappaport Faculty of Medicine,

Technion-Israel Institute of Technology,

Haifa, Israel
Practicing reproductive medicine clinicians still encounters this dilemma on a daily basis. Nonetheless, there is yet no clear strategy or guidelines how to act in these patients. If a negative association between $P$ elevation on the day of hCG administration and the probability of pregnancy exists, it might be worth examining the possibility of cryopreserving the resulting embryos and their transfer in a subsequent frozen-thawed cycles. Alternatively, administering hCG at an earlier time in the follicular phase, prior to $\mathrm{P}$ elevation may be suggested or yet another strategy should be searched for. Conversely, absence of an association indicates that assessment of serum $P$ throughout the follicular phase or on the day of hCG administration might be unnecessary.

\section{Progesterone elevation mechanism in the pre-GnRH analogues era}

During the pre-GnRH analogue era, premature luteinization has been shown to be the result of untimely LH surge causing moderate P elevation before hCG administration [4]. This phenomenon has shown to result in poor oocyte maturation, recovery, fertilization, and reduced embryo quality and was linked to low pregnancy and high abortion rates [5-8].

\section{Progesterone elevation mechanism in the GnRH analogues era}

During the early days of the GnRH agonist down-regulation treatment elevated $\mathrm{P}$ level was suggested to be the result of frank LH rise and incomplete pituitary desensitization [9], yet further reports did not confirm these findings. Prospective controlled studies employing the long GnRH agonist [10] as well as the antagonist [11] protocols did not show LH 
elevation despite $\mathrm{P}$ rise on the day of hCG administration in the presumed "premature luteinization" cycles. Moreover, LH addition to FSH treatment following GnRH agonist down-regulation did not increase $\mathrm{P}$ level during the follicular phase or on the day of hCG administration, as compared to FSH only stimulation [12-14].

Cumulative evidence in the last few years are gathering to suggest that $\mathrm{P}$ elevation, before the day of $\mathrm{hCG}$ administration, in a GnRH analogue cycles is the result of the $\mathrm{COH}$ itself, specifically a magnitude response to FSH rather than LH stimulation [2, 3, 14, 15]. Furthermore, LH co-administration to $\mathrm{FSH}$, in this setting, is capable of reducing, rather than elevating P level. This has been recently demonstrated in a large prospective controlled study performed in young normogonadotropic infertile patients undergoing ART treatment [16]. These findings were suggested to be in accordance with twocell two-gonadotropin theory [3]. In this setting, high FSH-only stimulation will recruit a large number of growing follicles leading to an increased ovarian steroidogenic activity and $\mathrm{P}$ production. Without an LH drive to the vascularized theca cells, $\mathrm{P}$ will not be further metabolized and will find its way to the circulation. Conversely, the addition of LH activity, in such a non-luteinized environment, may act to reduce circulating P, by promoting its conversion to androgens, which are then further metabolized to estrogens by the granulosa cells [3].

In addition, LH-like activity obtained from the hCG content of hMG, that has been previously suggested as a cause for elevated P level before hCG administration, presumably "premature luteinization" [17], has also been shown not to be the cause of this phenomenon [16].

Taken together, in a GnRH analogue ART setting the main mechanism responsible for $\mathrm{P}$ elevation prior to $\mathrm{hCG}$ administration is not $\mathrm{LH} / \mathrm{LH}$ like activity but high $\mathrm{FSH}$ dosage employed during stimulation, causing increased ovarian steroidogenic activity. Moreover, LH supplementation in such a non-luteinized environment lowers, rather increases $\mathrm{P}$ level prior to $\mathrm{hCG}$ administration.

\section{A call for a new terminology}

It is generally accepted that luteinization has a common stimulus, the pre-ovulatory LH surge [18]. P elevation in a luteinized environment is only possible following the exposure of theca and granulosa cells to LH or LH like activity. If $\mathrm{P}$ rises without a $\mathrm{LH}$ increase, the theca and granulosa cells remain intact and no luteinization develops. In a GnRH analogue cycle, P elevation on the day of hCG administration, does not seem to be the result of frank $\mathrm{LH}$ secretion. Therefore, the use of the term "premature luteinization" in all cycles is inappropriate and should be modified. Dragging the term of "premature luteinization" from the pre- to the GnRH analogue era is confusing and inadequate and other terminology should be looked for. The need for an appropriate nomenclature and definition that will reflect accurately this phenomenon and be able to guide investigators to examine the effect of $\mathrm{P}$ elevation on ART outcome, which is still to be very much controversial [1-3], is prominently needed.

Table 1 summarizes the different terms of $\mathrm{P}$ elevation before hCG administration, that have been recently suggested in the literature. It is clear that $\mathrm{P}$ elevation in this setting is follicular and its occurrence is prior to hCG administration. It is also evident that in young normo-gonadotropic patients undergoing $\mathrm{COH}$, $\mathrm{P}$ elevation does not develop in the early or the mid-follicular phase, but following day 6 of stimulation [16]. Whether the same mechanism and timing of $P$ elevation is also the case in low ovarian reserve women is still in question $[19,20]$. Furthermore, early follicular $\mathrm{P}$ elevation has already been demonstrated in infertile women with lateonset congenital adrenal hyperplasia undergoing $\mathrm{COH}$ and ART treatment [21, 22].

Therefore, to avoid confusion, the element of timing (such as late follicular, pre-hCG or on the day of hCG) is suggested to be removed from the new suggested terminology. Moreover, a prominent feature that should be emphasized in the new terminology is whether the elevated $\mathrm{P}$ during the follicular phase is originating from a luteinized or nonluteinized environment. Accordingly, the terms "elevated luteinized origin progesterone" (ELOP) and "elevated nonluteinized origin progesterone" (ENLOP) are suggested to differentiate between two different main mechanisms of elevated follicular P. According to recent evidence presented above, it seems that in most ART cases employing GnRH analogues, elevated $\mathrm{P}$ are from a non-luteinized origin and therefore the term ENLOP rather ELOP ought to be employed.
Table 1 Progesterone elevation during the follicular phase in the GnRH analogue ART cycles: ${ }^{a}$

\footnotetext{
${ }^{\mathrm{a}}$ The numbers in the brackets are the numbers of references.
}

Current terminology:

1. Premature luteinization

2. Elevated progesterone on the day of hCG administration [1, 2, 25]

3. Pre-hCG progesterone elevation [20]

4. Raised follicular phase progesterone concentration [3]

Suggested new terminology:

1. Elevated luteinized origin progesterone (ELOP)

2. Elevated non-luteinized origin progesterone (ENLOP) 


\section{A call for a new definition}

Traditionally, premature luteinization in the pre-GnRH analogue era has been defined as $\mathrm{P}$ level $>0.9 \mathrm{ng} / \mathrm{mL}$ on the day of hCG administration [4]. During the GnRH analogue era the term of premature luteinization was nonintentionally dragged from the previous period with the same definition. Although most investigators still apply an absolute P level on hCG day as an indication for elevated P level, the cut-off point has differed considerably between one study and another ranging from 0.9 to $2.0 \mathrm{ng} / \mathrm{mL}$ [1, 10]. Most recent studies have suggested that a cut-off point of 1.25 [16] or $1.5 \mathrm{ng} / \mathrm{mL}$ [2], may differentiate more properly in their detrimental effect on endometrial receptivity, however this should be investigated further taking into account the type of gonadotropin and $\mathrm{GnRH}$ analogue (agonist or antagonist) employed.

Since $\mathrm{P}$ elevation is linked to the $\mathrm{COH}$ itself, driven by high FSH dosage, it is clear that $\mathrm{P}$ elevation is positively correlated to estradiol $\left(\mathrm{E}_{2}\right)$ level on the day of $\mathrm{hCG}$ administration as well as number of retrieved oocytes, as has been recently demonstrated [1, 2]. Moreover, defining a single threshold for a detrimental serum $\mathrm{P}$ level on endometrial receptivity and clinical pregnancy achievement has been suggested to be imprecise [23], since other confounding variables including maximal $E_{2}$ level could affect the end result.

Therefore, to take into consideration the increase in the late follicular $\mathrm{P}$ level and to control for the ovarian response of each patient undergoing $\mathrm{COH}$, the $\mathrm{P} / \mathrm{E}_{2}$ ratio was introduced by our group $[10,24]$. Calculation of the $\mathrm{P} / \mathrm{E}_{2}$ ratio was performed as follows: $\mathrm{P}(\mathrm{ng} / \mathrm{mL}) \times 1,000 / \mathrm{E}_{2}(\mathrm{pg} / \mathrm{mL})$. Accordingly, in a GnRH analogue ART setting, a $\mathrm{P} / \mathrm{E}_{2}$ ratio of $>1$ may define more properly infertile patients developing elevated $\mathrm{P}$ before hCG administration or ENLOP as suggested. Prospective targeted studies are needed to evaluate the most appropriate way of definition taking into account the effect of this phenomenon on endometrial receptivity and pregnancy achievement.

Progesterone assays in the past were targeted to assess ovulation during the luteal phase. In a non-luteinized environment elevated $\mathrm{P}$ is $5-10$ folds lower than the luteal phase level. It is therefore crucial that only validated precise assays for moderate P elevation [25] in the follicular phase should be employed when planning any future study targeting this topic.

\section{Conclusion}

Despite the routine employment of GnRH analogues in modern $\mathrm{COH}$ for ART, elevated $\mathrm{P}$ level prior to $\mathrm{hCG}$ administration is still common. Accumulating evidence supports the notion that the mechanism responsible for $\mathrm{P}$ elevation is not LH/LH like activity but high FSH dosage employed during stimulation. Moreover, LH supplementation in such a non-luteinized environment lowers, rather increases, the P level before hCG administration. Therefore, the "premature luteinization" adopted from the non-GnRH analogue era is misleading and should be modified. The need for an appropriate nomenclature and definition that will reflect accurately this phenomenon and be able to guide the investigators to examine the effect $\mathrm{P}$ elevation on ART outcome, which is still to be very much controversial, is prominently needed. A new terminology and definition are suggested.

\section{References}

1. Venetis CA, Kolibianakis EM, Papanikolaou E, Bontis J, Devroey $\mathrm{P}$, Tarlatzis BC. Is progesterone elevation on the day of human chorionic gonadotrophin administration associated with the probability of pregnancy in in vitro fertilization? A systemic review and meta-analysis. Hum Reprod Update. 2007;13:343-55.

2. Bosch E, Labarta E, Crespo J, Simon C, Remohí, Jenkins J, et al. Circulating progesterone levels and ongoing pregnancy rates in controlled ovarian stimulation cycles for in vitro fertilization: analysis of over 4000 cycles. Hum Reprod. 2010;25:2092-100.

3. Fleming R, Jenkins J. The source and implications of progesterone rise during the follicular phase of assisted reproduction cycles. Reprod Biomed Online. 2010;21:446-9.

4. Younis J, Simon A, Laufer N. Endometrial preparation: lessons from oocyte donation. Fertil Steril. 1996;66:873-84.

5. Messinis IE, Templeton A, Baird DT. Endogenous luteinizing hormone surge during superovulation induction with sequential use of clomiphene citrate and pulsatile human menopausal gonadotropin. J Clin Endocrinol Metab. 1985;61:1076-80.

6. Stanger JD, Yovich JL. Reduced in-vitro fertilization of human oocytes from patients with raised basal luteinizing hormone levels during the follicular phase. Br J Obstet Gynaecol. 1985;92:85-93.

7. Lujueune B, Degueldre M, Camus M, Vekemans M, Opsomer L, Leroy F. In vitro fertilization and embryo transfer as related to endogenous luteinizing hormone rise or human chorionic gonadotropin administration. Fertil Steril. 1986;45:377-83.

8. Eibschitz I, Belaisch-Allart JC, Frydman R. In vitro fertilization management and results in stimulated cycles with a spontaneous luteinizing hormone discharge. Fertil Steril. 1986;45:231-6.

9. Hofmann GE, Bergh PA, Guzman I, Masuku S, Navot D. Premature luteinization is not eliminated by pituitary desensitization with leuprolide acetate in women undergoing gonadotrophin stimulation who demonstrated premature luteinization in a prior gonadotrophin-only cycle. Fertil Steril. 1993;8:695-8.

10. Younis JS, Matilsky M, Radin O, Ben-Ami M. Increased progesterone/estradiol ratio in the late follicular phase could be related to low ovarian reserve in in vitro fertilization - embryo transfer cycles with a long gonadotropin-releasing hormone agonist. Fertil Steril. 2001;76:294-9.

11. Bosch E, Valencia I, Escudero E, et al. Premature luteinization during gonadotrophin-releasing hormone antagonist cycles and its relationship with in vitro fertilization outcome. Fertil Steril. 2003;80:1444-9.

12. Adonakis G, Deshpande N, Yates RWS, Fleming R. luteinization hormone increases estradiol secretion but has no effect on progesterone concentrations in the late follicular phase of in vitro fertilization cycles in women treated with gonadotrophin-releasing 
hormone agonist and follicle-stimulating hormone. Fertil Steril. 1998;69:450-53.

13. Filicori M, Cognogni GE, Pocognoli E, et al. Modulation of folliculogenesis and steroidogenesis in women by graded menotropin administration. Hum Reprod. 2002;17:2009-15.

14. Filicori M, Cognogni GE, Pocognoli P, et al. Comparison of controlled ovarian stimulation with human menopausal gonadotrophin or recombinant follicle-stimulating hormone. Fertil Steril. 2003;80:390-7.

15. Ubaldi F, Camus M, Smitz J, Bennink HC, Van Steirteghem A, Devroey P. Premature luteinization in in vitro fertilization cycles using gonadotropin-releasing hormone agonist (GnRH-a) and recombinant follicle-stimulating hormone (FSH) and $\mathrm{GnRH}-\mathrm{a}$ and urinary FSH. Fertil Steril. 1996;66:275-80.

16. Andersen AN, Devroey P, Arce JC, MERIT Group. Clinical outcome following stimulation with highly purified hMG or recombinant FSH in patients undergoing IVF: a randomized assessor-blind controlled trial. Hum Reprod. 2006;21:3217-27.

17. Copperman AB, Horowitz GM, Kaplan P, Scott RT, Navot D, Hofmann GE. Relationship between circulating human chorionic gonadotropin levels and premature luteinization in cycles of controlled ovarian hyperstimulation. Fertil Steril. 1995;63:1267-71.

18. Murphy BD. Models of luteinization. Biol Reprod. 2000;63:2-11.
19. Younis JS. Elevated progesterone level on the day of hCG administration is related to FSH dose: is it all the truth? Hum Reprod. 2011;26:498-9. Epub 2010 Dec 15.

20. De Ziegler D, Bijaoui G, Chapron C. Pre-hCG elevation of plasma progesterone; good, bad or otherwise. Hum Reprod Update. 2008;14:393. Epub 2008 Jun 2.

21. Levran D, Ben-Shlomo I, Parientte C, Dor J, Mashiach S, Weissman A. Familial partial 17,20 desmolase and 17hydroxylase deficiency presenting as infertility. J Assist Reprod Genet. 2003;20:21-7.

22. De Ziegler D, Brioschi PA, Fanchin R, Bulleti C. Confronting the hidden face of progesterone during the follicular phase. J Assist Reprod Genet. 2003;20:29-32.

23. Bosch E. Comment on: is progesterone elevation on the day of human chorionic gonadotrophin administration associated with the probability of pregnancy in in vitro fertilization? A systematic review and meta-analysis. By Venetis et al (2007). Hum Reprod Update. 2008;14:194-5.

24. Younis JS, Haddad S, Matilsky M, Ben-Ami M. Premature luteinization: could it be an early manifestation of low ovarian reserve? Fertil Steril. 1998;69:461-5.

25. Fleming R. Progesterone elevation on the day of hCG: methodological issues. Hum Reprod Update. 2008;14:391-3. 